\title{
Psychological distress, perceived stigma, and coping among caregivers of patients with schizophrenia
}

This article was published in the following Dove Press journal:

Psychology Research and Behavior Management

16 August 2016

Number of times this article has been viewed

\author{
Hui Chien Ong' \\ Norhayati Ibrahim ${ }^{2}$ \\ Suzaily Wahab ${ }^{3}$
}

'Biomedical Science Programme, ${ }^{2}$ Health Psychology Programme,

Faculty of Health Sciences, Universiti Kebangsaan Malaysia, ${ }^{3}$ Department of Psychiatry, Faculty of Medicine, Pusat Perubatan Universiti Kebangsaan Malaysia, Cheras, Kuala Lumpur, Malaysia
Correspondence: Norhayati Ibrahim Health Psychology Programme, Faculty of Health Sciences, Universiti Kebangsaan Malaysia, Jalan Raja Muda A. Aziz, 50300 Kuala Lumpur, Malaysia

Tel +60326878174

Fax +60326878192

Email norhayati70@gmail.com
Abstract: Nowadays, family members are gradually taking on the role of full-time caregivers for patients suffering from schizophrenia. The increasing burden and tasks of caretaking can cause them psychological distress such as depression or anxiety. The aim of this study was to measure the correlation between perceived stigma and coping, and psychological distress as well as determine the predictors of psychological distress among the caregivers. Results showed that $31.5 \%$ of the caregivers experienced psychological distress. "Community rejection" was found to be positively associated with psychological distress. In case of coping subscales, psychological distress had a positive correlation with substance use, use of emotional support, behavioral disengagement, venting, and self-blame, while it was negatively correlated with "positive reframing". Behavioral disengagement was the best predictor of psychological distress among caregivers of patients with schizophrenia, followed by positive reframing, use of emotional support, self-blame, and venting. Health practitioners can use adaptive coping strategies instead of maladaptive for caregivers to help ease their distress and prevent further deterioration of psychological disorders.

Keywords: family caregivers, social stigma, coping skills, psychological stress, schizophrenia

\section{Introduction}

In Malaysia, most cases of deinstitutionalized patients are sent home to live with their families. Hence, family members become their primary, full-time caregivers. This might help improve the condition of some patients. However, Caqueo-Urízar et $\mathrm{al}^{1}$ stated that taking care of patients suffering from schizophrenia may impact the emotions and economy of the caregivers and cause physical distress. Past research has also found that caregivers experience increased psychological distress due to the burden of caregiving ${ }^{2}$ as it can be a very challenging task. ${ }^{3,4}$

Psychological distress is defined as the discomfort of a patient while experiencing symptoms of disorders or anxiety before and after treatment. ${ }^{5}$ It refers to the context of strain, stress, and distress. Past research often described it as an emotional suffering condition with symptoms of depression and anxiety. ${ }^{6,7}$ These symptoms can range from a person showing disinterest, feeling sad, or losing hope to depression, anxiety, nervousness followed by some somatic symptoms such as headache, fatigue, and insomnia. ${ }^{8}$ Psychological distress is not merely associated with the inability to conduct daily chores, but it is also a measure of the other psychiatric disorder symptoms, such as major depression and generalized anxiety disorder. ${ }^{9}$

Caregivers also tend to experience social problems because of the people around them. Magaña et $\mathrm{al}^{10}$ found that perceived stigma and symptoms of depression among 
caregivers were significantly associated. Struening et $\mathrm{al}^{11}$ reported that society often relates serious mentally ill patients with violence and $70 \%$ of the respondents included in their study believed that such patients were dangerous. This leads to a stereotype and discrimination against caregivers making it even more difficult for them to seek help and support from others. It could also result in symptoms of serious distress such as depression, sadness, anxiety, physical disorder, and demoralization to the stigmatized person. ${ }^{11}$

In the face of the psychological distress and societal problems, although some of these strategies help reduce their burden or stress, others are not particularly helpful. Kausar and Powell ${ }^{12}$ found that the caregivers of patients with neurological disorders who used emotional coping experienced higher distress than those who used problem coping. In India, the caregivers of patients suffering from schizophrenia were found using both adaptive and maladaptive coping strategies. ${ }^{13,14}$ Coping strategies such as reinterpretation, ${ }^{15}$ positive life growth, ${ }^{15}$ social support, ${ }^{16}$ usage of religion or spirituality, ${ }^{16}$ active coping, ${ }^{16}$ acceptance, ${ }^{16}$ and positive reframing ${ }^{16}$ were found to be positively associated with lower distress. ${ }^{16}$ On the other hand, coping strategies such as self-blame, ${ }^{16}$ avoidance, ${ }^{17}$ and mental disengagement ${ }^{15}$ were positively correlated with higher distress.

Past research had focused on the correlation of stigma or coping with psychological distress among caregivers of different countries and their populations. ${ }^{10-12,15-17}$ Perceived stigma was found to predict psychological distress among caregivers of schizophrenic patients, ${ }^{10,11}$ major depression, ${ }^{11}$ and bipolar disorder. ${ }^{11}$ Some research studies state that problem-focused coping can give positive results while emotion-focused coping can be related to poor adaptation ${ }^{18,19}$ among caregivers of patients with neurological disorders. ${ }^{12}$ Other studies have found that coping strategies such as greater positive reframing, acceptance, and lesser self-blame can mediate between the patient's illness identity and the caregivers' belief in the patient's level of personal control over the illness. ${ }^{16}$ Avoidance ${ }^{17}$ was associated with higher distress, while acceptance and social and instrumental support were related to lower distress among caregivers of terminally ill patients. ${ }^{17}$

There is a lack of studies that focus on the psychological distress among caregivers of patients with schizophrenia in Malaysia. ${ }^{20}$ Although past research has found significant association between the demographic profiles of caregivers and their overall well-being, ${ }^{21-30}$ distress can have considerably profound effect on the caregivers and lead to psychological disorders. Hence, this study aims to provide some data that can help understand and mitigate the psychological distress of caregivers. It also highlights the relationship between stigma and use of coping strategies to psychological distress. The results obtained from this study could potentially act as reference for health and clinical professionals to implement suitable and effective programs and interventions for the caregivers.

Based on the past studies, the level of psychological distress experienced by caregivers was found to be affected by their perceived stigma ${ }^{10,11}$ and coping strategies used ${ }^{15-17}$ during the caregiving process. Hence, this study aims to examine the correlation between perceived stigma and coping, and the psychological distress among caregivers of patients with schizophrenia in Malaysia, and also determine the factors that predict the psychological distress among these caregivers.

\section{Methodology}

Two hundred caregivers of schizophrenic outpatients were recruited from the Psychiatric Clinic of Hospital Canselor Tuanku Muhriz for this cross-sectional study. The research was conducted using self-rated questionnaires. The study included caregivers from three major ethnic groups in Malaysia (namely Malay, Indian, and Chinese). The patients had been previously diagnosed with schizophrenia by psychiatrists using the Diagnostic and Statistical Manual of Mental Disorders (DSM)-IV diagnostic criteria. The inclusion criteria for study are as follows: the caregiver, defined as an individual responsible for the patient's daily activities including basic and instrumental functions and for monitoring patients, ${ }^{22}$ must have been 18 years old or above; have had no reported psychiatric illness; and must have been in close contact with the patient for at least 6 months. Only consenting caregivers were included in the study.

The study was conducted from April to July 2015 using the purposive sampling method. Researchers began the recruitment process by obtaining the names and identification numbers of the visiting schizophrenia patients from the outpatient record book at the Psychiatric Clinic. Caregivers who accompanied the patients were identified and included in the study. They were approached while waiting for the outpatients' sessions at the clinic. Written informed consent was obtained before the distribution of questionnaires. Each questionnaire (both the English and Malay versions) consisted of four sections: sociodemographic profiles, Kessler's K10 Psychological Distress Scale, Devaluation of Consumer Scale (DCS) and Devaluation of Consumer Families Scale (DCFS), and Brief COPE. Data pertaining to the questionnaires were obtained by a researcher with a professional background in 
psychology. This research was approved by the Universiti Kebangsaan Malaysia Research Ethics Committee.

\section{Sociodemographic profiles}

This section included information about the caregivers: age, sex, religion, marital status, residential location, level of education, working status, duration of caregiving, and relationship with the outpatient; and details about the outpatient: age, frequency of admission to psychiatric ward, frequency of admission to psychiatric ward during the current year, and frequency of appointments with psychiatric doctors within the last 6 months.

\section{Kessler's K IO Psychological Distress Scale}

The K10 scale is a short instrument to measure psychological distress levels such as depression and anxiety, which was designed by Kessler et al. ${ }^{31}$ This scale can be administered by the normal population or patients. It comprises ten questions pertaining to the respondent's emotional state within the last month and uses a cutoff score of 20 to determine whether the respondent is likely to be distressed. Scores 10-19 show that there is no sign of any distress, 20-24 mild distress, 25-29 moderate distress, and 30-50 severe distress. ${ }^{32}$ The reliability value of the scale was 0.93 in a sample of caregivers of cancer patients in Guam, USA, ${ }^{33}$ and 0.91 in Malaysia among a student sample. ${ }^{34}$ The reliability value of the K10 scale for this study was 0.87 .

\section{DCS and DCFS}

The DCS and DCFS were designed by Struening et $\mathrm{al}^{11}$ for caregivers of psychologically ill patients. The DCS comprises eight questions measuring the extent of the caregiver's belief in the devaluation of someone with mental illness, and it consists of three factors, namely status reduction, role restriction, and friendship refusal. The DCFS comprises seven questions with the purpose of measuring the extent of belief of the caregivers in the social devaluation of families with one or more mental patients, and it includes three factors, namely "community rejection", "causal attribution", and "uncaring parents". The original overall scale reliability was 0.71 , and the overall scale reliability for this study was 0.79 , thereby indicating that it was a suitable scale for use in the present context.

\section{Brief COPE}

This 28 -item scale was developed by Carver ${ }^{35}$ in order to determine the coping methods used when trying to face a problem. It is divided into 14 subscales, namely self-distraction, active coping, denial, substance use, use of emotional support, use of instrumental support, behavioral disengagement, venting, positive reframing, planning, humor, acceptance, religion, and self-blame. It is a suitable questionnaire to measure coping strategies. ${ }^{36,37}$ The validation survey in Malaysia showed that the overall internal consistency of Brief COPE was 0.83 with most coping strategies having Cronbach's alpha values of $>0.5 .{ }^{36}$ In the present study, the overall internal consistency was 0.69 .

\section{Statistical analysis}

The data in this study were analyzed using the IBM SPSS Statistics 22 (IBM Corporation, Armonk, NY, USA). Descriptive statistics were used to evaluate the sociodemographic profiles, level of psychological distress, and mean and standard deviation of the components. Pearson's correlation was used to analyze the relationship between factors of DCS, DCFS, and Brief COPE with psychological distress. Lastly, multiple regression analysis was used to determine the predictors of psychological distress based on significant relationships revealed by the correlation tests.

\section{Results}

The sociodemographic profiles of the 200 respondents showed that they were primarily from middle adulthood and females. Malaysia is a multiracial country consisting of three major ethnic groups - Malay, Chinese, and Indian. Majority of the respondents were Malays and Chinese and followed Islam or Buddhism. In addition, the results also showed that most of them were married, lived in the city, and had the highest education up to the secondary level. The number of working respondents was similar to the number of nonworking respondents. Most of them had taken care of the patients with schizophrenia for more than 3 years, and majority of them were parents or children of the patients (Table 1).

It was found that the respondents were most likely to be well (68.5\%); however, $\sim 31.5 \%$ of the respondents were reported as being likely to have psychological distress. Table 2 shows the outpatient's age and frequency of admission to psychiatric ward and frequency of appointment with psychiatrist.

The mean and standard deviation of the scores from the respondents were calculated. It was found that for psychological distress, caregivers were likely to be well since the mean was $<20$. For perceived stigma, all the components showed average perceived stigma, except the "uncaring parents" where respondents mostly did not agree that most people blame their parents for the mental illness of their children. For coping, results showed that the respondents used active 
Table I Sociodemographic profiles of respondents

\begin{tabular}{|c|c|c|}
\hline Variable & Frequency (n) & $\%$ \\
\hline \multicolumn{3}{|l|}{ Age } \\
\hline Early adulthood & 50 & 25.0 \\
\hline Middle adulthood & 109 & 54.5 \\
\hline Late adulthood & 41 & 20.5 \\
\hline \multicolumn{3}{|l|}{ Sex } \\
\hline Male & 86 & 43.0 \\
\hline Female & 114 & 57.0 \\
\hline \multicolumn{3}{|l|}{ Race } \\
\hline Malay & 89 & 44.5 \\
\hline Chinese & 83 & 41.5 \\
\hline Indian & 28 & 14.0 \\
\hline \multicolumn{3}{|l|}{ Religion } \\
\hline Islam & 88 & 44.0 \\
\hline Buddhism & 64 & 32.0 \\
\hline Hinduism & 23 & 11.5 \\
\hline Christianity & 19 & 9.5 \\
\hline Other religions & 6 & 3.0 \\
\hline \multicolumn{3}{|l|}{ Marital status } \\
\hline Single & 24 & 12.0 \\
\hline Married & 156 & 78.0 \\
\hline Divorced/widowed & 20 & 10.0 \\
\hline \multicolumn{3}{|l|}{ Residential location } \\
\hline City & 176 & 88.0 \\
\hline Suburban & 24 & 12.0 \\
\hline \multicolumn{3}{|l|}{ Highest education } \\
\hline Primary & 30 & 15.0 \\
\hline Secondary & 101 & 50.5 \\
\hline Tertiary & 69 & 34.5 \\
\hline \multicolumn{3}{|l|}{ Working status } \\
\hline Working & 99 & 49.5 \\
\hline Not working & 101 & 50.5 \\
\hline \multicolumn{3}{|l|}{ Duration of caregiving } \\
\hline $0-3$ years & 38 & 19.0 \\
\hline$>3$ years & 162 & 81.0 \\
\hline \multicolumn{3}{|c|}{ Relationship with patient } \\
\hline Spouse & 44 & 22.0 \\
\hline Parent/child & 121 & 60.5 \\
\hline Sibling & 27 & 13.5 \\
\hline Other family member & 8 & 4.0 \\
\hline
\end{tabular}

Table 2 Age and frequency of admission to psychiatric ward of the outpatients

\begin{tabular}{lll}
\hline Variable & Mean & $\begin{array}{l}\text { Standard } \\
\text { deviation }\end{array}$ \\
\hline Age & 43.36 & 15.88 \\
$\begin{array}{l}\text { Frequency of admission to psychiatric ward } \\
\text { Frequency of admission to psychiatric ward }\end{array}$ & 2.49 & 4.36 \\
$\begin{array}{l}\text { within this year } \\
\begin{array}{l}\text { Frequency of appointment with psychiatrist } \\
\text { within the last 6 months }\end{array}\end{array}$ & 2.77 & 2.39 \\
\hline
\end{tabular}

coping, positive reframing, acceptance, and religion. Coping strategies such as substance use and behavioral disengagement were seldom adopted (Table 3).

Table 4 shows the correlation between the factors that denote perceived stigma, coping subscales, and
Table 3 Mean and SD of components

\begin{tabular}{llll}
\hline Scales & Components & Mean & SD \\
\hline KIO & Psychological distress & 17.80 (out of 50) & 7.08 \\
DCS & Status reduction & 2.49 (out of 4) & 0.509 \\
& Role restriction & 2.64 & 0.549 \\
& Friendship refusal & 2.56 & 0.73 \\
DCFS & Community rejection & 2.26 & 0.60 \\
& Causal attribution & 2.21 & 0.64 \\
& Uncaring parents & 1.87 & 0.68 \\
Brief COPE & Self-distraction & 5.11 (out of 8) & 1.83 \\
& Active coping & 6.42 & 1.45 \\
& Denial & 3.07 & 1.41 \\
& Substance use & 2.28 & 0.93 \\
& Emotional support & 4.66 & 1.87 \\
& Instrumental support & 4.90 & 1.98 \\
& Behavioral disengagement & 2.58 & 1.18 \\
& Venting & 4.31 & 1.77 \\
& Positive reframing & 6.23 & 1.70 \\
& Planning & 5.96 & 1.91 \\
& Humor & 3.40 & 1.66 \\
& Acceptance & 6.70 & 1.44 \\
& Religion & 6.24 & 2.13 \\
& Self-blame & 3.02 & 1.47 \\
\hline
\end{tabular}

Abbreviations: DCFS, Devaluation of Consumer Families Scale; DCS, Devaluation of Consumer Scale; SD, standard deviation.

Table 4 Correlation between psychological distress with DCS and DCFS factors and Brief COPE subscales

\begin{tabular}{ll}
\hline Components & Psychological distress \\
\hline DCS & 0.110 \\
Status reduction & 0.020 \\
Role restriction & 0.105 \\
Friendship refusal & \\
DCFS & $0.155^{*}$ \\
Community rejection & 0.128 \\
Causal attribution & 0.002 \\
Uncaring parents & \\
Brief COPE & -0.007 \\
Self-distraction & -0.042 \\
Active coping & 0.053 \\
Denial & $0.148^{*}$ \\
Substance use & $0.161^{*}$ \\
Use of emotional support & 0.105 \\
Use of instrumental support & $0.405^{* *}$ \\
Behavioral disengagement & $0.225^{* *}$ \\
Venting & $-0.172^{*}$ \\
Positive reframing & -0.068 \\
Planning & 0.044 \\
Humor & -0.052 \\
Acceptance & 0.088 \\
Religion & $0.292^{* *}$ \\
Self-blame & \\
\hline
\end{tabular}

Notes: $* P<0.05, * * P<0.01$.

Abbreviations: DCFS, Devaluation of Consumer Families Scale; DCS, Devaluation of Consumer Scale.

psychological distress among caregivers. Prior to calculating the correlations, the assumption of normality of psychological distress was found to be supported and all caregivers participated only once. Pearson's correlation indicated only 
"community rejection" factor for perceived stigma to be positively associated with psychological distress. For coping subscales, it was found that substance use, use of emotional support, behavioral disengagement, venting, and self-blame were positively correlated with psychological distress. Positive reframing was found to be negatively correlated with psychological distress.

Multiple regression analysis was performed to determine the predictors of psychological distress. The assumption of normality was not violated. The relatively high tolerance for all predictors in the regression model indicated that multicollinearity did not interfere with the outcome. Results from the multiple regression analysis showed that use of emotional support, behavioral disengagement, venting, positive reframing, and self-blame contributed to $25.6 \%$ of the psychological distress, $R^{2}=0.256, R^{2}$-adjusted $=0.229, F(7,192)=9.457, P=0.000$. Behavioral disengagement was the best predictor of psychological distress followed by positive reframing, use of emotional support, self-blame, and venting among caregivers of patients with schizophrenia.

\section{Discussion}

The present study showed that more than half the sample of respondents did not exhibit any psychological distress, whereas $\sim 31.5 \%$ of the caregivers experienced mild to great psychological distress. Previous studies have reported that $\sim 83 \%{ }^{38,39}$ and $72 \%$ of the caregivers face psychological distress. ${ }^{40}$ In Ethiopia, the overall prevalence of psychological distress among caregivers of patients with severe mental illnesses was $\sim 56.7 \%{ }^{41}$ However, a previous study conducted in Malaysia among caregivers of patients with schizophrenia showed the prevalence to be only $14 \%{ }^{42}$

One of the factors that may explain the difference in the prevalence of psychological distress among the caregivers is the study setting. Respondents in the present study were the caregivers of schizophrenic outpatients. As compared to the inpatients, many of these outpatients were generally more stable and did not suffer from relapses. This could be a plausible reason for the lower levels of distress among the caregivers in our study. The frequency of admission to psychiatric ward within this year was very low, indicating that the illness was not very critical. Also, longer duration of caregiving may lessen the caregiver's stress and burden as they get accustomed to the illness and learn how to manage the patient. ${ }^{28,43}$ This was demonstrated by the caregivers in our study who had been staying with the patients for $>3$ years.
"Community rejection" from perceived stigma was found to be positively correlated with caregivers' psychological distress. Similar to the findings of Magaña et al, ${ }^{10}$ stigma was also found to be significantly related to caregivers' symptoms of depression. Another study by Mubarak et $\mathrm{al}^{44}$ showed that the stigma surrounding patients with schizophrenia also caused social rejection and unfair blame. The caregivers' beliefs that most people will look down upon them, avoid making friends with them, or would be reluctant to keep in touch with their families could stop them from seeking help and social support when needed. ${ }^{45}$ It has also reportedly caused negative consequences in terms of social relationships, work, and the health of the stigmatized person. ${ }^{46}$ In addition, the need to be able to cope with challenging issues and to provide good care with the perceived stigma can result in more stress to the caregivers. ${ }^{11}$

Surprisingly, this study also found that there was a lack of association between most perceived stigma factors and psychological distress. Goffman ${ }^{47}$ stated that a normal person and a stigmatized person were differentiated by their own perspectives, ${ }^{48}$ where it depended on caregivers themselves to view the stigma as a burden in their daily lives or not. Past research suggests that psychological distress of the caregivers could also be affected by other factors such as poor social support, ${ }^{41}$ clinical status of patients, ${ }^{41}$ and sociodemographic factors. ${ }^{41,49}$

In our study, some coping strategies such as substance use, use of emotional support, behavioral disengagement, and venting were found to be positively correlated with psychological distress and, hence, considered to be maladaptive coping strategies. Positive reframing was negatively correlated with psychological distress. In the long run, substance use such as consuming alcohol or other drugs may affect the caregiver's health and increase distress. Although many past studies have shown that using emotional and instrumental support were negatively correlated with the distress experienced by caregivers, ${ }^{17,50}$ the findings of our study showed a positive correlation between the coping mechanism and the caregiver's distress. Seeking emotional support from friends or relatives could be problematic especially when caring for the mentally ill. Previous studies have reported how a mentally ill patient can create issues or problems in the family dynamics and relationships. ${ }^{11,48}$ Some studies have also found that too much social support can lead to more psychological distress, especially when the given support is controlling or directive.$^{51}$ The matching hypothesis also indicated that social support would be most effective if it matched the needs of the receiver. ${ }^{52,53}$ 
Coping strategies such as behavioral disengagement, venting, and self-blame were more closely related to emotionfocused coping. Kausar and Powell ${ }^{12}$ found that caregivers who used emotion-focused coping strategies had higher distress that led to poor adaptation ${ }^{18,19}$ than those using problem-focused coping which brought positive results. ${ }^{18,19}$ On the other hand, similar to the findings of Fortune et al, ${ }^{16}$ positive reframing was found to reduce the psychological distress levels of caregivers in the present study. Hence, we suggest that this coping strategy should be adopted by caregivers in order to lower their level of distress.

The present study also analyzed the predictors of psychological distress. It was found that behavioral disengagement was the highest predictor, followed by positive reframing, use of emotional support, self-blame, and venting. As some of the coping strategies were maladaptive, we suggest that caregivers should avoid using coping strategies that can cause them more distress and instead adopt more adaptive coping strategies.

The distress level of caregivers was found to be associated with community rejection. Also, some coping strategies were unsuitable for the caregiving process. In order to eliminate community rejection, clinicians and health practitioners should target on educating the public and address the communities' concerns, fear toward patients with mental illness such as schizophrenia. In addition, interventions on adaptive coping strategies could be introduced to the caregivers to further alleviate their distress when caring for their family members with schizophrenia. This can positively affect the patients in the long run.

\section{Limitations}

This study focused only on the caregivers of patients with schizophrenia from one tertiary hospital that received many references from external organizations. Hence, the results cannot be representative of the overall population of caregivers in Malaysia. This cross-sectional study lacked a comparison between caregivers' psychological distress during different periods of time. This was intentionally excluded from the study to avoid affecting the outcome by confounding variables such as caregiver's gross income, their daily contact time with the patients, and clinical status of the patients (severity of symptoms, comorbidity, level of functioning, and persistence of positive and negative symptoms). Future research could be replicated in different hospitals in Malaysia, and researchers could consider conducting a longitudinal study to gain a better insight into the factors causing psychological distress among caregivers.

\section{Conclusion}

The findings from the present study showed that almost onethird of the caregivers of schizophrenia patients were affected by psychological distress. This study also showed that the caregivers' psychological distress was partly associated with perceived stigma and the coping strategies used. Some coping strategies were found to be predictive of psychological distress; hence, we suggested against using some of those strategies. Targeting these two important areas in the intervention plan by educating both the public and the caregivers is definitely crucial, not only to ensure the overall well-being of the caregivers, but also for long-term improvement in the schizophrenic patients.

\section{Acknowledgments}

The researchers would like to thank all the caregivers who participated in this research as well as the health practitioners in Hospital Canselor Tuanku Muhriz and all those who assisted this research. The authors report that this work is supported by the Fundamental Research Grant Scheme (FRGS/1/2014/SS02/UKM/02/2) from the Ministry of Higher Education Malaysia.

\section{Disclosure}

The authors report no conflicts of interest in this work.

\section{References}

1. Caqueo-Urízar A, Gutiérrez-Maldonado J, Miranda-Castillo C. Quality of life in caregivers of patients with schizophrenia: a literature review. Health Qual Life Outcomes. 2009;7:84.

2. Mitsonis C, Voussoura E, Dimopoulos N, et al. Factors associated with caregiver psychological distress in chronic schizophrenia. Soc Psychiatry Psychiatr Epidemiol. 2012;47(2):331-337.

3. Koujalgi SR, Patil SR. Family burden in patient with schizophrenia and depressive disorder: a comparative study. Indian J Psychol Med. 2013;35(3):251

4. Li J, Lambert CE, Lambert VA. Predictors of family caregivers' burden and quality of life when providing care for a family member with schizophrenia in the People's Republic of China. Nurs Health Sci. 2007;9(3):192-198.

5. Ridner SH. Psychological distress: concept analysis. J Adv Nurs. 2004;45(5):536-545.

6. Mirowsky J, Ross CE. Social Causes of Psychological Distress. New Jersey: Transaction Publishers; 2003.

7. Drapeau A, Marchand A, Beaulieu-Prévost D. Epidemiology of psychological distress. In: L'Abate L, editor. Mental Illnesses - Understanding, Prediction and Control. Croatia: InTech; 2012.

8. Kirmayer LJ. Cultural variations in the response to psychiatric disorders and emotional distress. Soc Sci Med. 1989;29(3):327-339.

9. Watson D. Differentiating the mood and anxiety disorders: a quadripartite model. Ann Rev Clin Psychol. 2009;5:221-247.

10. Magaña SM, García JIR, Hernández MG, Cortez R. Psychological distress among Latino family caregivers of adults with schizophrenia: the roles of burden and stigma. Psychiatr Serv. 2007;58(3):378-384.

11. Struening EL, Perlick DA, Link BG, Hellman F, Herman D, Sirey JA. Stigma as a barrier to recovery: the extent to which caregivers believe most people devalue consumers and their families. Psychiatr Serv. 2001;52(12):1633-1638. 
12. Kausar R, Powell GE. Coping and psychological distress in carers of patients with neurological disorders. Asia Pacific Disabil Rehab J. 1999;10(2):64-68.

13. Chadda RK, Singh TB, Ganguly KK. Caregiver burden and coping. Soc Psychiatry Psychiatr Epidemiol. 2007;42(11):923-930.

14. Chakrabarti S, Gill S. Coping and its correlates among caregivers of patients with bipolar disorder: a preliminary study. Bipolar Disord. 2002;4(1):50-60.

15. Cooke M, Peters E, Fannon D, et al. Insight, distress and coping styles in schizophrenia. Schizophr Res. 2007;94(1):12-22.

16. Fortune DG, Smith JV, Garvey K. Perceptions of psychosis, coping, appraisals, and psychological distress in the relatives of patients with schizophrenia: an exploration using self-regulation theory. $\mathrm{Br} \mathrm{J}$ Clin Psychol. 2005;44(3):319-331.

17. Goldzweig G, Merims S, Ganon R, Peretz T, Baider L. Coping and distress among spouse caregivers to older patients with cancer: an intricate path. J Geriatr Oncol. 2012;3(4):376-385.

18. Folkman S, Lazarus RS, Dunkel-Schetter C, DeLongis A, Gruen RJ. Dynamics of a stressful encounter: cognitive appraisal, coping, and encounter outcomes. J Pers Soc Psychol. 1986;50(5):992.

19. Vitaliano PP, DeWolfe DJ, Maiuro RD, Russo J, Katon W. Appraised changeability of a stressor as a modifier of the relationship between coping and depression: a test of the hypothesis of fit. J Pers Soc Psychol. 1990;59(3):582.

20. Balasubramanian N, D'Sa JL. Knowledge Questionnaire on Home Care of Schizophrenics (KQHS): validity and reliability. J Educ Pract. 2013;4(11):176-182.

21. Awadalla AW, Ohaeri JU, Salih AA, Tawfiq AM. Subjective quality of life of family caregivers of community living Sudanese psychiatric patients. Soc Psychiatry Psychiatr Epidemiol. 2005;40(9):755-763.

22. Conde-Sala JL, Garre-Olmo J, Turró-Garriga O, López-Pousa S, Vilalta-Franch J. Factors related to perceived quality of life in patients with Alzheimer's disease: the patient's perception compared with that of caregivers. Int J Geriatr Psychiatr. 2009;24(6):585-594.

23. Sales E. Family burden and quality of life. Qual Life Res. 2003;12(1):33-41.

24. Martyns-Yellowe I. The burden of schizophrenia on the family. A study from Nigeria. Br J Psychiatr. 1992;161(6):779-782.

25. Moily S, Murthy R, Puttamma M, Kishore Kumar K, Hiremath S Burden in families with schizophrenic patients in a rural community. Indian J Psychiatr. 1997;39(1):48.

26. Adeosun II. Correlates of caregiver burden among family members of patients with schizophrenia in Lagos, Nigeria. Schizophr Res Treat 2013;2013:353809.

27. Lua PL, Bakar ZA. Health-related quality of life profiles among family caregivers of patients with schizophrenia. Fam Community health. 2011;34(4):331-339.

28. Wong DFK, Lam AYK, Chan SK, Chan SF. Quality of life of caregivers with relatives suffering from mental illness in Hong Kong: roles of caregiver characteristics, caregiving burdens, and satisfaction with psychiatric services. Health Qual Life Outcomes. 2012;10:15.

29. Wang J, Zhao X. Quality of life and social support in spouses of patients with depression. Int J Psychosoc Rehabil. 2012;16:28-35.

30. Trivedi RB, Bryson CL, Udris E, Au DH. The influence of informal caregivers on adherence in COPD patients. Ann Behav Med. 2012;44(1):66-72.

31. Kessler RC, Andrews G, Colpe LJ, et al. Short screening scales to monitor population prevalences and trends in non-specific psychological distress. Psychol Med. 2002;32(6):959-976.

32.Victorian Department of Health \& Human Services. Victorian population health survey 2001: selected findings; 2001. Available from https://www2.health.vic.gov.au/getfile/?sc_itemid=\%7BF5D69CF4-83FF4EC2-9610-9AC1F63F1407\%7D\&title=Victorian\%20population\%20 health $\% 20$ survey $\% 202001 \% 3 \mathrm{~A} \% 20$ Selected $\% 20$ findings.
33. Macaraeg JC, Smith ST. Psychological distress and help-seeking attitudes of cancer caregivers on Guam. Pacific Asia Inq. 2013;4(1):121-135.

34. Rajiah K, Coumaravelou S, Ying OW. Relationship of test anxiety, psychological distress and academic motivation among first year undergraduate pharmacy students. Int J Appl Psychol. 2014;4(2):68-72.

35. Carver CS. You want to measure coping but your protocol'too long: consider the brief cope. Int J Behav Med. 1997;4(1):92-100.

36. Yusoff MSB. The validity of the Malay Brief COPE in identifying coping strategies among adolescents in secondary school. Int Med J. 2011;18:29-33.

37. Yusoff N, Low W, Yip C. Reliability and validity of the Brief COPE Scale (English version) among women with breast cancer undergoing treatment of adjuvant chemotherapy: a Malaysian study. Med J Malaysia. 2010;65(1):41-44.

38. Magliano L, Fiorillo A, De Rosa C, Malangone C, Maj M; Group NMHPW. Family burden in long-term diseases: a comparative study in schizophrenia vs. physical disorders. Soc Sci Med. 2005;61(2):313-322.

39. Magliano L, Marasco C, Fiorillo A, Malangone C, Guarneri M, Maj M. The impact of professional and social network support on the burden of families of patients with schizophrenia in Italy. Acta Psychiatr Scand. 2002;106(4):291-298.

40. Shah STH, Sultan SM, Faisal M, Irfan M. Psychological distress among caregivers of patients with schizophrenia. J Ayub Med Coll Abbottabad. 2013;25(3-4):27-30.

41. Sintayehu M, Mulat H, Yohannis Z, Adera T, Fekade M. Prevalence of mental distress and associated factors among caregivers of patients with severe mental illness in the outpatient unit of Amanuel Hospital, Addis Ababa, Ethiopia, 2013: cross-sectional study. J Mol Psychiatry. 2015;3(1):1.

42. Osman A, Gutierrez PM, Smith K, Fang Q, Lozano G, Devine A. The Anxiety Sensitivity Index-3: analyses of dimensions, reliability estimates, and correlates in nonclinical samples. J Pers Assess. 2010;92(1):45-52.

43. McCullagh E, Brigstocke G, Donaldson N, Kalra L. Determinants of caregiving burden and quality of life in caregivers of stroke patients. Stroke. 2005;36(10):2181-2186.

44. Mubarak A, Baba I, Chin LH, Hoe QS. Quality of life of communitybased chronic schizophrenia patients in Penang, Malaysia. Aust $N Z J$ Psychiatry. 2003;37(5):577-585.

45. Corrigan PW. On the Stigma of Mental Illness: Practical Strategies for Research and Social Change. Washington: American Psychological Association; 2005.

46. Hanafiah AN, Van Bortel T. A qualitative exploration of the perspectives of mental health professionals on stigma and discrimination of mental illness in Malaysia. Int J Mental Health Syst. 2015;9(1):1.

47. Goffman, E. Stigma: Notes on the Management of Spoiled Identity. Englewood Cliffs, NJ: Prentice-Hall; 1963.

48. Östman M, Kjellin L. Stigma by association: psychological factors in relatives of people with mental illness. $\mathrm{Br} J$ Psychiatry. 2002;181(6):494-498.

49. Yusuf AJ, Nuhu FT. Factors associated with emotional distress among caregivers of patients with schizophrenia in Katsina, Nigeria. Soc Psychiatry Psychiatr Epidemiol. 2011;46(1):11-16.

50. Cox C. Comparing the experiences of black and white caregivers of dementia patients. Soc Work. 1995;40(3):343-349.

51. Lewis MA, Rook KS. Social control in personal relationships: impact on health behaviors and psychological distress. Health Psychol. 1999; 18(1):63.

52. Cohen S, McKay G. Social support, stress and the buffering hypothesis: a theoretical analysis. In: Baum A, Singer JE, Taylor SE, editors. Handbook of Psychology and Health. 4th Vol. Hillsdale, NJ: Erlbaum; 1984: 253-267.

53. Cohen S, Wills TA. Stress, social support, and the buffering hypothesis. Psychol Bull. 1985;98(2):310. 


\section{Publish your work in this journal}

Psychology Research and Behavior Management is an international, peerreviewed, open access journal focusing on the science of psychology and its application in behavior management to develop improved outcomes in the clinical, educational, sports and business arenas. Specific topics covered in the journal include: Neuroscience, memory and decision making; Behavior modification and management; Clinical applications; Business and sports performance management; Social and developmental studies; Animal studies. The manuscript management system is completely online and includes a very quick and fair peer-review system, which is all easy to use. Visit http://www. dovepress.com/testimonials.php to read real quotes from published authors.

Submit your manuscript here: https://www.dovepress.com/psychology-research-and-behavior-management-journal 